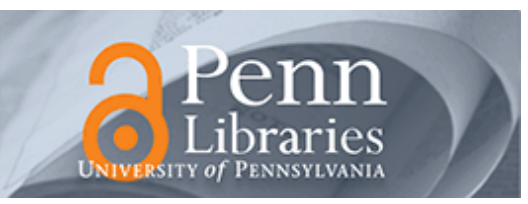

University of Pennsylvania

ScholarlyCommons

Departmental Papers (CBE)

Department of Chemical \& Biomolecular

Engineering

September 2007

\title{
Identification and characterization of 3-substituted pyrazolyl esters as alternate substrates for cathepsin B: The confounding effects of DTT and cysteine in biological assays
}

\author{
Michael C. Myers \\ University of Pennsylvania \\ Andrew D. Napper \\ University of Pennsylvania \\ Nuzhat Motlekar \\ University of Pennsylvania \\ Parag P. Shah \\ University of Pennsylvania \\ Chun-Hao Chiu \\ University of Pennsylvania
}

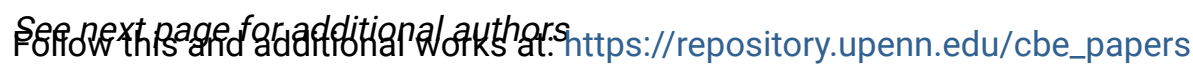

\section{Recommended Citation}

Myers, M. C., Napper, A. D., Motlekar, N., Shah, P. P., Chiu, C., Beavers, M. P., Diamond, S. L., Huryn, D. M., \& Smith, A. B. (2007). Identification and characterization of 3-substituted pyrazolyl esters as alternate substrates for cathepsin B: The confounding effects of DTT and cysteine in biological assays. Retrieved from https://repository.upenn.edu/cbe_papers/97

Postprint version. Published in Bioorganic \& Medicinal Chemistry Letters, Volume 17, Issue 17, September 2007, pages 4761-4766.

Publisher URL: http://dx.doi.org/10.1016/j.bmcl.2007.06.091

This paper is posted at ScholarlyCommons. https://repository.upenn.edu/cbe_papers/97

For more information, please contact repository@pobox.upenn.edu. 


\title{
Identification and characterization of 3-substituted pyrazolyl esters as alternate substrates for cathepsin B: The confounding effects of DTT and cysteine in biological assays
}

\author{
Abstract \\ Substituted pyrazole esters were identified as hits in a high throughput screen (HTS) of the NIH Molecular \\ Libraries Small Molecule Repository (MLSMR) to identify inhibitors of the enzyme cathepsin B. Members \\ of this class, along with functional group analogs, were synthesized in an effort to define the structural \\ requirements for activity. Analog characterization was hampered by the need to include a reducing agent \\ such as dithiothreitol (DTT) or cysteine in the assay, highlighting the caution required in interpreting \\ biological data gathered in the presence of such nucleophiles. Despite the confounding effects of DTT \\ and cysteine, our studies demonstrate that the pyrazole 1 acts as alternate substrate for cathepsin B, \\ rather than as an inhibitor. \\ Keywords \\ cathepsin b, DTT, cysteine, alternate substrate, HTS, Q3 MLSMR, pyrazole esters \\ Comments \\ Postprint version. Published in Bioorganic \& Medicinal Chemistry Letters, Volume 17, Issue 17, September \\ 2007, pages 4761-4766. \\ Publisher URL: http://dx.doi.org/10.1016/j.bmcl.2007.06.091 \\ Author(s) \\ Michael C. Myers, Andrew D. Napper, Nuzhat Motlekar, Parag P. Shah, Chun-Hao Chiu, Mary Pat Beavers, \\ Scott L. Diamond, Donna M. Huryn, and Amos B. Smith III
}




\section{Identification and characterization of 3-substituted pyrazolyl esters as alternate substrates for cathepsin B: The confounding effects of DTT and cysteine in biological assays}

Michael C. Myers, ${ }^{\text {a,b }}$ Andrew D. Napper, ${ }^{\text {a,c }}$ Nuzhat Motlekar, ${ }^{\text {a,c }}$ Parag P. Shah, ${ }^{\mathrm{a}, \mathrm{c}}$ Chun-Hao Chiu, ${ }^{\mathrm{a}, \mathrm{c}}$ Mary Pat Beavers, ${ }^{\mathrm{a}, \mathrm{c}}$ Scott L. Diamond, ${ }^{\mathrm{a}, \mathrm{c}}$ Donna M. Huryn ${ }^{\mathrm{a}, \mathrm{b}, *}$ and Amos B. Smith, III ${ }^{\mathrm{a}, \mathrm{b}, *}$

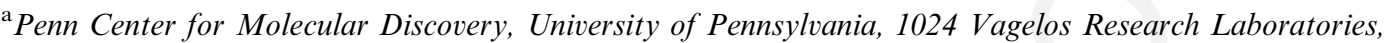
Philadelphia, PA 19104-6383, USA

${ }^{\mathrm{b}}$ Department of Chemistry, University of Pennsylvania, 231 South 34th Street, Philadelphia, PA 19104-6323, USA ${ }^{\mathrm{c}}$ Institute for Medicine and Engineering, University of Pennsylvania, 1024 Vagelos Research Laboratories, Philadelphia, PA 19104-6383, USA

Abstract-Substituted pyrazole esters were identified as hits in a high throughput screen (HTS) of the NIH Molecular Libraries Small Molecule Repository (MLSMR) to identify inhibitors of the enzyme cathepsin B. Members of this class, along with functional group analogs, were synthesized in an effort to define the structural requirements for activity. Analog characterization was hampered by the need to include a reducing agent such as dithiothreitol (DTT) or cysteine in the assay, highlighting the caution required in interpreting biological data gathered in the presence of such nucleophiles. Despite the confounding effects of DTT and cysteine, our studies demonstrate that the pyrazole 1 acts as alternate substrate for cathepsin B, rather than as an inhibitor.

(C) 2007 Elsevier Ltd. All rights reserved.

Cathepsins play an important role in cellular protein degradation through the lysosomal pathway, ${ }^{1}$ and as such, represent a significant class of drug targets, having been implicated in a variety of degenerative and invasive processes including: asthma, Alzheimer's disease, ${ }^{2}$ cancer, ${ }^{3,4}$ diabetes, inflammatory diseases, ${ }^{5}$ liver disorders, multiple sclerosis, muscular dystrophy, and pancreatitis. ${ }^{6}$ The large number of disease states associated with the biological effects of the cathepsin protease family, and specifically cathepsin B, demands an understanding of their biological function. The availability of small molecule probes of the cathepsins thus holds the promise both for characterization of this ubiquitous enzyme class and for the discovery of new cysteine protease inhibitors of considerable biomedical value. , $^{3,7}$

Keywords: Cathepsin B; DTT; Cysteine; Alternate substrate; HTS; Q3 MLSMR; Pyrazole esters.

* Corresponding authors. E-mail: huryn@sas.upenn.edu
Recently, the Penn Center for Molecular Discovery $(\mathrm{PCMD})^{9}$ completed a high throughput screen (HTS) to identify small molecule probes (i.e., inhibitors) for the papain-like cysteine protease family, including cathepsins $\mathrm{B}, \mathrm{L}$, and $\mathrm{S}$. While a number of both potent and selective inhibitors have been described previously, ${ }^{2-8}$ this project presented an opportunity to annotate the NIH Molecular Libraries Small Molecule Repository (MLSMR) through deposition of data in PubChem. ${ }^{10}$ As such, this work represents one of the first efforts to create a comprehensive, publicly available profile of smallmolecule inhibitors of the cysteine protease class. Screening 63,332 members of the MLSMR against human liver cathepsin B resulted in a number of hits. ${ }^{11}$ Further confirmatory assays included $\mathrm{IC}_{50}$ determination and elimination of false positives resulting from non-specific redox chemistry. ${ }^{12}$ Based on these results, a family of substituted pyrazole esters was identified that displayed promising activity as inhibitors of cathepsin B (Table 1). ${ }^{13}$ 
Table 1. Pyrazole HTS hits in the cathepsin B assay

\begin{tabular}{llll} 
& \\
\hline PubChem SID & $\mathrm{X}$ & $\mathrm{R}$ & $\mathrm{IC}_{50}{ }^{\mathrm{a}}(\mu \mathrm{M})$ \\
\hline 4249135 (1) & $\mathrm{S}$ & $\mathrm{H}$ & $0.25 \pm 0.03$ \\
4247730 (2) & $\mathrm{S}$ & $\mathrm{F}$ & $0.44 \pm 0.11$ \\
4245669 (3) & $\mathrm{S}$ & $\mathrm{OMe}$ & $0.69 \pm 0.10$ \\
844213 (4) & $\mathrm{S}$ & $\mathrm{Me}$ & $1.99 \pm 0.17$ \\
$849441(\mathbf{5})$ & $\mathrm{O}$ & $\mathrm{Me}$ & $1.75 \pm 0.06$ \\
845259 (6) & $\mathrm{O}$ & $\mathrm{F}$ & $1.26 \pm 0.04$ \\
\hline
\end{tabular}

${ }^{\mathrm{a}} \mathrm{IC}_{50}$ values are reported as means \pm standard deviation (number of

The pyrazole series (1-6) displayed suitable physicochemical properties (MW 347-379 and $\mathrm{X} \log P=2.7$ 3.3 ) with structurally related analogs revealing a range of activities in our HTS analysis. Based on these attributes, members of this series were viewed as potential small molecule lead compounds for the inhibition of cathepsin B, and as such were selected for further study to understand and improve their biological profile.

Structurally related pyrazoles that were inactive in the HTS assay were compared to compounds 1-6 in a preliminary effort to understand the requirements for activity. Based on this analysis, we pinpointed the ester group as a functional moiety important for activity; we reasoned that the ester could act as an electrophilic site that would react with the active site cysteine. Alternatively, the compound could behave as an alternate substrate of the enzyme resulting in transesterification or hydrolysis of the ester functionality. To differentiate these two scenarios, a series of analogs were constructed and subjected to biochemical and analytical studies to define the

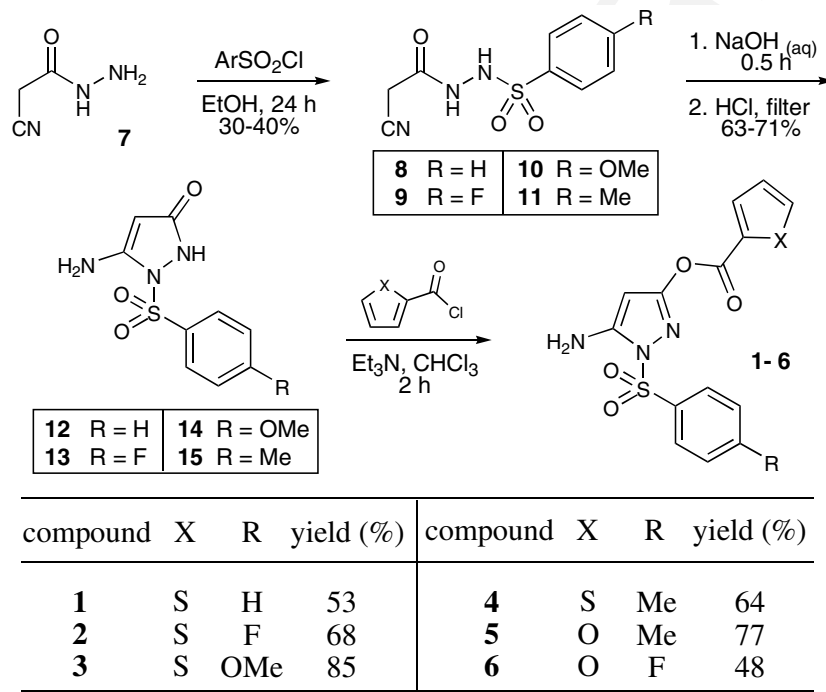

Scheme 1. Synthetic procedure to prepare pyrazole esters 1-6. determinations $=3$ ) mechanism of action. Herein we report the results of this effort.

To confirm both the activity and identity of the original hits, we resynthesized compounds $1-6 .{ }^{14,15}$ This exercise permitted both the development of an effective method to construct the pyrazole scaffold and the preparation of analogs. The synthesis of 1,3-disubstituted-5-aminopyrazoles (1-6) began with commercially available cyanoacetohydrazide (7) and the appropriate arylsubstituted sulfonyl chlorides, according to the procedure of Elgemeie et al. ${ }^{16,17}$ Reaction of 7 with the arylsubstituted sulfonyl chlorides in ethanol furnished the sulfonamides 8-11 which conveniently precipitated from solution (Scheme 1).

As expected, the major by-products, aryl ethyl sulfonates, remained soluble and were easily removed from 8-11 via filtration. Thus, on a $50 \mathrm{mmol}$ scale, gram quantities of the required sulfonamide hydrazides could be readily prepared in high purity. Efficient cyclizations of sulfonamide hydrazides $(\mathbf{8}-\mathbf{1 1})$ to pyrazolones $(\mathbf{1 2}-\mathbf{1 5})$ occurred upon treatment with an aqueous solution of $\mathrm{NaOH}$, followed by acidification $(10 \% \mathrm{HCl})$ to precipitate the pyrazolones. ${ }^{18}$ The pyrazolones were used in the subsequent acylation step without purification. For example, treatment of 12-15 with 2-thiophenecarbonyl chloride or 2-furancarbonyl chloride in chloroform resulted in chemoselective ${ }^{19}$ acylation at the C3-oxygen versus the C5-amino group to furnish pyrazoles 1-6 in moderate to good yields after silica gel chromatography.

The availability of newly synthesized pyrazoles 1-6 allowed confirmation of the structures and observed biological activity of the initial hits. Pleasingly, both the structures and re-assay $\mathrm{IC}_{50}$ values of synthetic pyrazoles 1-6 were in agreement with the results obtained from the original screening experiments (Table 1).

The ester carbonyl carbon in $\mathbf{1}$, activated by the adjacent pyrazole, is a likely site for nucleophilic attack by the active site cysteine-25 sulfur in cathepsin B. In order to assess the electrophilicity of this carbon atom, equilibrium geometries and electrostatic potential surfaces were calculated for 1 using PC Spartan software. ${ }^{20}$ The known cysteine protease inhibitor $\mathbf{E 6 4}{ }^{21}$ was also analyzed for

As expected, the most electrophilic center for pyrazole ester 1 was the carbonyl carbon of the ester, with an electrostatic potential value of $128.0 \mathrm{~kJ} / \mathrm{mol}$. The carbons
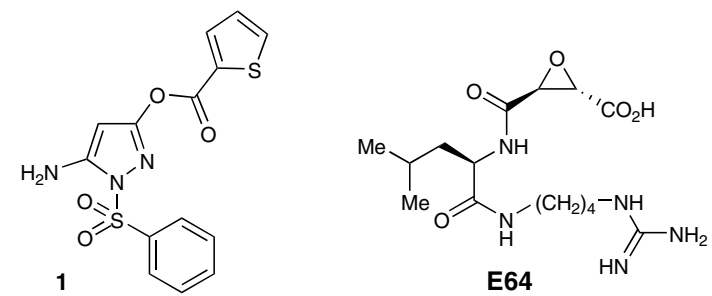

Figure 1. Compounds for which electrostatic potential surfaces were calculated: pyrazole ester 1 and E64. comparison to pyrazole ester 1 (Fig. 1). 
of the epoxide ring in E64 had values of 104.3 and 104.7 for their electrostatic potential surface energies. The greater positive value of $128.0 \mathrm{~kJ} / \mathrm{mol}$ suggests that the carbonyl carbon of $\mathbf{1}$ is more prone to nucleophilic attack than the epoxide carbons in the irreversible cathepsin B inhibitor E64. This difference in electrophilicity was confirmed experimentally (vide infra). Presumably, the stability of the pyrazolone by-product of 1 provides the driving force for attack of this atom center.

We reasoned that, modulating the electronic parameters of the electrophilic ester functionality in this series of compounds would quickly validate or eliminate the importance of this structural feature. To test this hypothesis, pyrazole $\mathbf{1 4}$ was employed as a common intermediate to construct ether 16, sulfonate $\mathbf{1 7}$, and isonicotinoyl ester $\mathbf{1 8}$ (Fig. 2).

Ether $\mathbf{1 6}$ was formed via an alkylation of $\mathbf{1 4}$ with 2-bromomethyl-thiophene ${ }^{22}$ in moderate yield. Sulfonate $\mathbf{1 7}$ and isonicotinoyl ester $\mathbf{1 8}$ were constructed under chemoselective acylation conditions similar to those employed to prepare pyrazoles 1-6. ${ }^{19}$ In support of the requirement of the ester functionality for biological activity, ether $\mathbf{1 6}$ and sulfonate $\mathbf{1 7}$ were found to be inactive. Surprisingly, however, related ester analog pyridine 18 was devoid of activity, despite its steric and electronic similarity to the thiophene moiety found in $\mathbf{1}$. This unexpected result led us to question the stability of the pyrazole hits (e.g., hydrolysis or transesterification) under the assay conditions. To probe these issues, we undertook further biological characterization of $\mathbf{1}$, as well as a detailed analysis of assay by-products. Kinetic analysis of the inhibition of cathepsin B by 1 revealed a competitive inhibition pattern, in which 1 increased the $K_{\mathrm{m}}$ of the substrate but had no effect on the $V_{\max }$. The $K_{\mathrm{i}}$ of 1 was determined to be $0.9 \mu \mathrm{M}( \pm) 0.25 \mu \mathrm{M}$ (Fig. 3). ${ }^{23}$

Reversibility of inhibition was next demonstrated by incubating cathepsin B with $\mathbf{1}$ at a concentration that gave complete inhibition followed by determination of enzyme activity after 100 -fold dilution. As expected for reversible inhibition, the enzyme regained full activity upon dilution. ${ }^{24}$

These experiments ruled out the possibility that $\mathbf{1}$ acts similar to E64, an irreversible inhibitor. The possibility
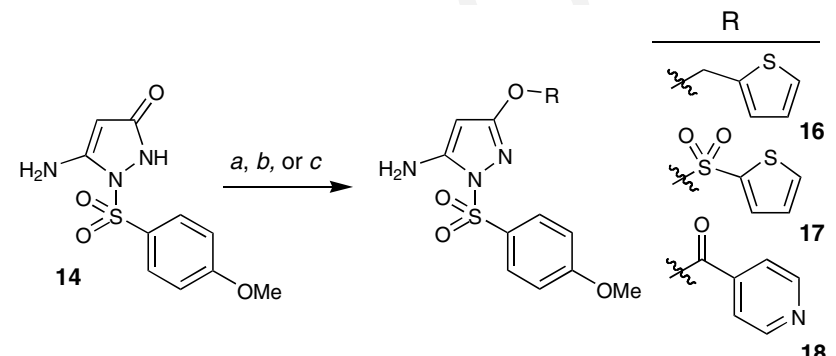

Figure 2. Reagents and conditions: (a) 2-bromomethyl-thiophene, $\mathrm{K}_{2} \mathrm{CO}_{3}$, DMF, 0-23 ${ }^{\circ} \mathrm{C}, 3 \mathrm{~h}, 50 \%$; (b) thiophene-2-sulfonyl chloride, $\mathrm{Et}_{3} \mathrm{~N}, \mathrm{CHCl}_{3}, 23^{\circ} \mathrm{C}, 2 \mathrm{~h}, 76 \%$; (c) isonicotinoyl chloride, $\mathrm{Et}_{3} \mathrm{~N}, \mathrm{CHCl}_{3}$, $23^{\circ} \mathrm{C}, 2 \mathrm{~h}, 43 \%$.
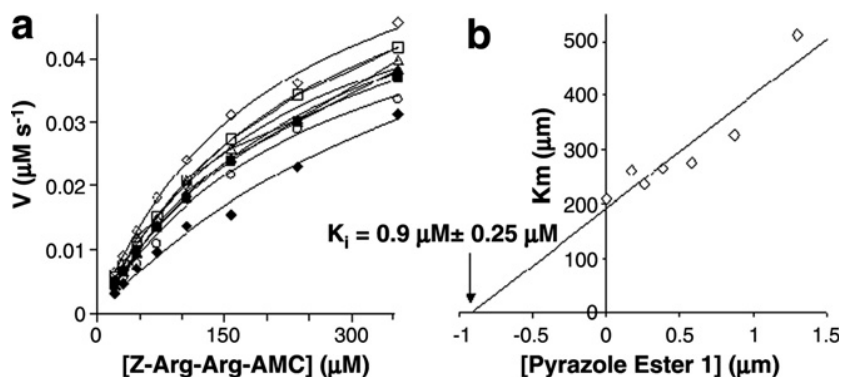

Figure 3. Kinetic characterization of inhibition of cathepsin $B$ by $\mathbf{1}$. Cathepsin B was assayed with combinations of 20-350 $\mu \mathrm{M}$ Z-Arg-ArgAMC substrate and $0.17-1.3 \mu \mathrm{M}$ inhibitor (1). Initial rates of product release were determined by measuring increase in fluorescence over $15 \mathrm{~min}$. Data were fit by non-linear regression using IDBS XLfit. (a) Rate of enzyme-catalyzed substrate hydrolysis as a function of its concentration. Substrate concentration was varied from 20 to $350 \mu \mathrm{M}$ in the presence of $0 \mu \mathrm{M}(\diamond), 0.17 \mu \mathrm{M}(\square), 0.25 \mu \mathrm{M}(\triangle), 0.39 \mu \mathrm{M}(\mathbf{\square})$, $0.58 \mu \mathrm{M}(\mathbf{\Delta}), 0.87 \mu \mathrm{M}(\bigcirc)$, and $1.3 \mu \mathrm{M}(\diamond)$ compound 1. (b) Replot of $K_{\mathrm{m}}$ values calculated by non-linear fit of curves in (a). Linear regression gave a $K_{\mathrm{i}}$ value of $0.9 \mu \mathrm{M}$ with a standard error of $0.25 \mu \mathrm{M}$.

that $\mathbf{1}$ acted as a substrate of cathepsin B, however, remained. That is, under the conditions employed for the kinetic analyses, a competitive inhibitor is indistinguishable from an alternate substrate. ${ }^{23}$ Thus, experiments were carried out to evaluate the reactivity of $\mathbf{1}$ under the assay conditions.

As a control, a biochemical time course experiment was designed. Pyrazole 1 was combined with the assay buffer (phosphate, $\mathrm{pH} 6.8$ ) over a series of time points $(0,2,17$, and $24 \mathrm{~h}$ ). Samples at each time point were then incubated with cathepsin B $(0.1 \mathrm{nM})$ in the buffer $(100 \mathrm{mM})$ containing dithiothreitol (DTT) $(2 \mathrm{mM})$ under the standard assay conditions, and $\mathrm{IC}_{50}$ data were measured. ${ }^{13}$ Results from these experiments indicated a significant loss of inhibitory activity which correlated with the time of pre-incubation (Table 2).

The $\mathrm{IC}_{50}$ values of pyrazole 1 increased from $1.42 \mu \mathrm{M}$ at a pre-incubation time of $0 \mathrm{~h}$ to $>50 \mu \mathrm{M}$ at an incubation time of $24 \mathrm{~h}$. Two additional experiments were conducted to pinpoint the cause of the time dependent loss of activity: (1) pyrazole 1 was added to an assay buffer that did not contain DTT (Column 2, Table 2); and (2) pyrazole 1 was added to a non-buffered solution also without DTT (Column 3, Table 2). Both experiments revealed that the $\mathrm{IC}_{50}$ values changed slightly from the 0

Table 2. Time dependent pre-incubation of $\mathbf{1}$ with and without DTT: an analysis of $\mathbf{1}$ in the cathepsin B assay

\begin{tabular}{lcll}
\hline $\begin{array}{l}\text { Pre-incubation } \\
\text { time (h) }\end{array}$ & \multicolumn{3}{c}{$\mathrm{IC}_{50}{ }^{\mathrm{a}}(\mu \mathrm{M})$} \\
\cline { 2 - 4 } & $\begin{array}{l}\text { Assay buffer } \\
\text { with DTT }\end{array}$ & $\begin{array}{l}\text { Assay buffer } \\
\text { without } \text { DTT }\end{array}$ & $\begin{array}{l}\text { Non-buffered } \\
\text { without } \text { DTT }\end{array}$ \\
\hline 0 & 1.4 & 0.8 & 0.8 \\
2 & 9.0 & 1.4 & 1.7 \\
17 & 45.4 & 0.7 & 1.8 \\
24 & $>50$ & 3.2 & 5.0
\end{tabular}

${ }^{\mathrm{a}} \mathrm{IC}_{50}$ values are calculated from a dose response curve of 162 -fold dilutions. 
to $24 \mathrm{~h}$ incubation time. Thus, the presence of DTT was deemed largely responsible for the significant loss in activity.

With these results in hand, we set out to define more precisely the role of DTT in the inactivation of $\mathbf{1}$. Analytical experiments were designed to mimic the biological preincubation experiment, wherein the aqueous solutions of 1 with and without DTT would be analyzed via LC-MS for hydrolysis products (e.g., pyrazolone 12). The LC-MS analysis corroborated the previous study and also provided an additional detail, the loss of $\mathbf{1}$ was the result of its conversion to pyrazolone $\mathbf{1 2}$ (Table 3).

For example, when 1 was incubated in the DTT containing assay buffer, conversion to $\mathbf{1 2}$ occurred quickly with $28 \%$ of 1 remaining after $1 \mathrm{~h}$, and only $12 \%$ after $24 \mathrm{~h} .{ }^{25}$ Hydrolysis of 1 to $\mathbf{1 2}$ also occurred, albeit slowly, in both buffer without DTT and non-buffered water. However, on the time-scale of the HTS assay, the contribution of this degradation pathway to the activity was negligible. Additional experiments indicated that when E64 was exposed to DTT (under the same conditions as listed in Table 3.) it was found to be stable with no E64 decomposition and no DTT-E64 adduct formed, as monitored by LC-MS.

Anticipating that $\mathbf{1 2}$ could arise via nucleophilic displacement of the thiophene ester with DTT, we examined the LC-MS data for the anticipated transesterified DTT-thiophene ester product 19 (Scheme 2).

Table 3. Time dependent pre-incubation of $\mathbf{1}$ with and without DTT: an analysis of 1 by LC-MS
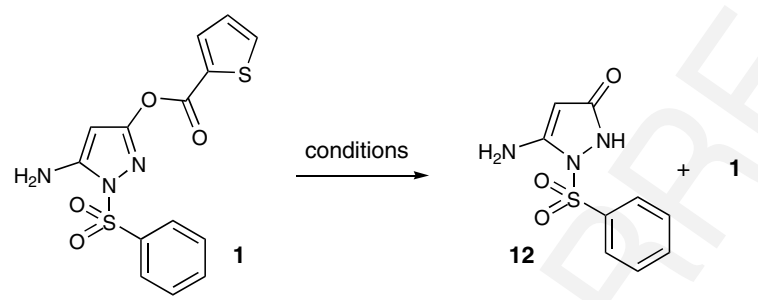

\begin{tabular}{clcc}
\hline \multirow{2}{*}{$\begin{array}{l}\text { Incubation } \\
\text { time (h) }\end{array}$} & \multicolumn{3}{c}{$\%$ conversion of $\mathbf{1 - 1 2}$} \\
\cline { 2 - 4 } & $\begin{array}{l}\text { Assay buffer } \\
\text { with DTT }\end{array}$ & $\begin{array}{c}\text { Assay buffer } \\
\text { without } \text { DTT }\end{array}$ & $\begin{array}{c}\text { Non-buffered } \\
\text { without } \text { DTT }\end{array}$ \\
\hline 1 & 72 & 5 & 5 \\
2 & 80 & 5 & 6 \\
16 & 87 & 13 & 11 \\
24 & 88 & 17 & 9 \\
\hline
\end{tabular}

${ }^{\mathrm{a}} \mathrm{LC}-\mathrm{MS}$ analysis conducted on a $6.5 \mathrm{~min}$ run time $(100 \mu \mathrm{M}$ sample concentration).

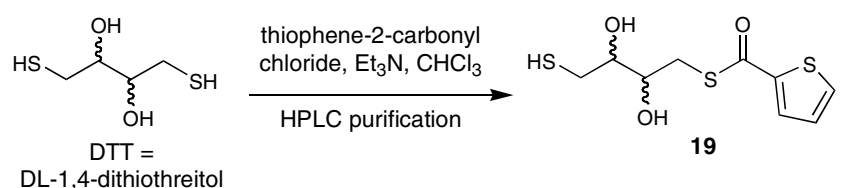

Scheme 2. Synthesis of DTT-thiophene adduct 19.
The molecular ion corresponding to $19(\mathrm{M}+1=265)$ was observed in the LC-MS analysis of the assay buffer with DTT. As further verification, adduct 19 was synthesized independently using DTT and 2-thiophenecarbonyl chloride, and used as a standard in the LC-MS analysis. Bioassay of $\mathbf{1 9}$ with cathepsin B revealed no activity. Taken together, these data reveal the basis for the diminished $\mathrm{IC}_{50}$ values following extended pre-incubation times.

The inherent redox chemistry associated with DTT is well known, both in connection with the identification of false positives in cysteine protease assays and with enzymes such as phosphatases. ${ }^{12,26-28}$ To avoid the redox issues of DTT, cysteine is often used in place of DTT due to its lower oxidation potential. Less well appreciated, however, is the propensity of DTT to act as a nucleophile, thereby confounding bioassay results. ${ }^{29,30}$ Unfortunately, in our case, replacement of DTT with cysteine does not alleviate the problem. Indeed, the same fast conversion of 1-12 was observed, via LC-MS, in the presence of cysteine. Thus, the series of pyrazole esters is susceptible to both the hydrolysis and transesterification pathways. We were, however, intrigued by the apparent lack of any activity of 18, despite the similar size and electronic attributes of the ester moiety. To explore this observation, we analyzed the rate of hydrolysis and transesterification of 18. Surprisingly, incubation of $\mathbf{1 8}$ in assay buffer, with and without DTT, and a non-buffered aqueous solution, revealed rapid conversion (ca. $1 \mathrm{~h})$ to pyrazolone 14, regardless of the presence of DTT (Table 4). ${ }^{25}$

The ease of hydrolysis and esterification of $\mathbf{1 8}$ is likely a reflection of the fact that the pyridine ring is partially protonated under the conditions. ${ }^{31}$ Thus, within the timescale of the cathepsin B assay $(1 \mathrm{~h}$ incubation with the enzyme), a negligible amount 18 would be present.

Taken together, the results support the hypothesis that $\mathbf{1}$ acts as an alternate cathepsin B substrate rather than an

Table 4. Time dependent pre-incubation of $\mathbf{1 8}$ with and without DTT: an analysis of 18 by LC-MS

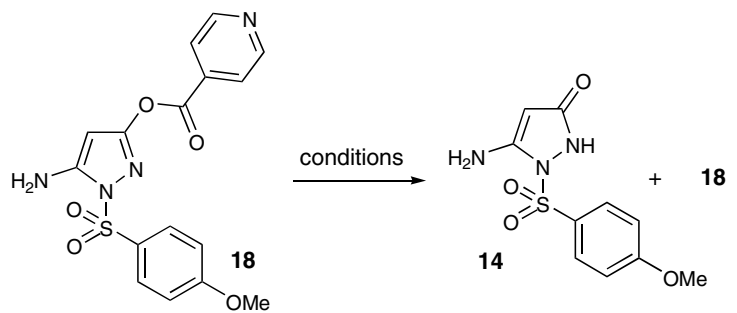

\begin{tabular}{llll}
\hline \multirow{2}{*}{$\begin{array}{l}\text { Incubation } \\
\text { time (h) }\end{array}$} & \multicolumn{3}{c}{$\%$ conversion of 18-14 } \\
\cline { 2 - 4 } & $\begin{array}{l}\text { Assay buffer } \\
\text { with DTT }\end{array}$ & $\begin{array}{l}\text { Assay buffer } \\
\text { without } \text { DTT }\end{array}$ & $\begin{array}{l}\text { Non-buffered } \\
\text { without DTT }\end{array}$ \\
\hline 1 & $>99$ & 41 & 15 \\
2 & $>99$ & 80 & 24 \\
16 & $>99$ & $>99$ & 95 \\
24 & $>99$ & $>99$ & 99 \\
\hline${ }^{\text {a }}$ LC-MS analysis conducted on a 6.5 min run time $(100 \mu \mathrm{M}$ sample \\
concentration).
\end{tabular}


Table 5. Standard assay conditions with and without cathepsin B: a stoichiometric reaction analyzed by $\mathrm{LC}-\mathrm{MS}^{\mathrm{a}}$
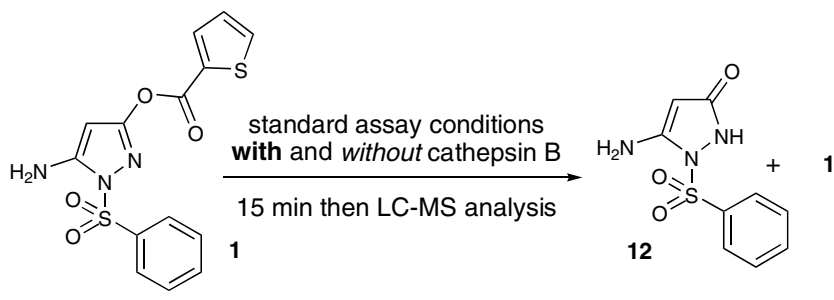

\begin{tabular}{ll}
\hline $\begin{array}{l}\text { Assay conditions } \\
\text { with cathepsin B }\end{array}$ & $\begin{array}{l}\text { Assay conditions } \\
\text { without cathepsin B }\end{array}$ \\
\hline $0 \%$ remaining $\mathbf{1}$ & $50 \%$ remaining $\mathbf{1}$ \\
\hline
\end{tabular}

${ }^{a}$ LC-MS analysis conducted on a 6.5 minute run time $(20 \mu \mathrm{M}$ cathepsin $\mathrm{B} ; 10 \mu \mathrm{M} \mathbf{1})$.

inhibitor. Presumably, the active site cysteine acts much like DTT to transesterify $\mathbf{1}$, and thereby forms a transient thiophenoyl-enzyme intermediate. ${ }^{7,32,33}$ To test this scenario, a stoichiometric reaction was devised to incubate pyrazole ester 1 (1 equiv) with and without cathep$\sin \mathrm{B}$ ( 2 equiv) (Table 5).

Under these stoichiometric reaction conditions, in the presence of cathepsin B, pyrazole $\mathbf{1}$ was fully converted to 12 after only $15 \mathrm{~min}$. However, under identical conditions, in the absence of cathepsin B, $50 \%$ of pyrazole 1 remained. ${ }^{34}$ We conclude that pyrazole esters such as $\mathbf{1}$ are competitive substrates for the enzyme cathepsin B.

In summary, we have demonstrated that pyrazole 1 acts as an alternate substrate for the cysteine protease, cathepsin B. Synthesis and evaluation of related analogs revealed the potential reactivity of the ester functionality with the nucleophilic enzyme active site cysteine to form a transient thiphenoyl-enzyme intermediate. Initially, the similar reactivity of DTT and cysteine, in the bioassay, confounded the HTS and subsequent assay results due to the nucleophilic properties of the thiol sulfur. Thus, it is important for the biological and chemical communities to consider the potential of DTT and cysteine to act as nucleophiles in assay systems where substrates contain electrophilic functionality.

\section{Acknowledgments}

Financial support for this work was provided by the NIH (5U54HG003915-02). We thank Professor Barry S. Cooperman for helpful discussions. We also thank Dr. Patrick J. Carroll for X-ray structural determination of pyrazole ester $\mathbf{2}$.

\section{References and notes}

1. McGrath, M. E. Annu. Rev. Biophys. Biomol. Struct. 1999, 28,181

2. Hook, V.; Toneff, T.; Bogyo, M.; Greenbaum, D.; Medzihradszky, K. F.; Neveu, J.; Lane, W.; Hook, G.; Reisine, T. Biol. Chem. 2005, 386, 931.

3. Michaud, S.; Gour, B. J. Exp. Opin. Ther. Patents 1998, 6, 645 .
4. Frlan, R.; Gobec, S. Curr. Med. Chem. 2006, 13, 2309.

5. Greenspan, P. D.; Clark, K. L.; Tommasi, R. A.; Cowen, S. D.; McQuire, L. W.; Farley, D. L.; van Duzer, J. H.; Goldberg, R. L.; Zhou, H.; Du, Z.; Fitt, J. J.; Coppa, D. E.; Fang, Z.; Macchia, W.; Zhu, L.; Capparelli, M. P.; Goldstein, R.; Wigg, A. M.; Doughty, J. R.; Bohacek, R. S.; Knap, A. K. J. Med. Chem. 2001, 44, 4524.

6. Schirmeister, T.; Kaeppler, U. Mini-Rev. Med. Chem. 2003, 3, 361 .

7. Otto, H.-H.; Schirmeister, T. Chem. Rev. 1997, 97, 133.

8. Hernandez, A. A.; Roush, W. R. Curr. Opin. Chem. Biol. 2002, 6, 459.

9. Penn Center for Molecular Discovery: http://www.seas. upenn.edu/ pcmd/ Molecular Library Screening Center Network: http://nihroadmap.nih.gov/molecularlibraries/.

10. PubChem: http://pubchem.ncbi.nlm.nih.gov/.

11. PubChem web address for PCMD cathepsin B hits: http:// www.ncbi.nlm.nih.gov/entrez/query.fcgi?db=pcassay\& term $=488,453,523$.

12. Tjernber, A.; Hallén; Schultz, J.; James, S.; Benkestock, Q2 K.; Byström, S.; Weigelt, J. Bioorg. Med. Chem. Lett. 2004, 14, 891.

13. Compounds were serially diluted in DMSO and transferred into the assay microplate using a $100-\mathrm{nL}$ pintool to give 16 dilutions ranging from $50 \mu \mathrm{M}$ to $1.5 \mathrm{nM}$. Triplicate plates were set up in this manner to give three independently calculated $\mathrm{IC}_{50}$ values for each compound. Cathepsin B (Calbiochem 219362) was activated by incubating with assay buffer for $15 \mathrm{~min}$. Assay buffer consisted of $100 \mathrm{mM}$ sodium-potassium phosphate, $\mathrm{pH} 6.8$ (86 mM potassium phosphate, monobasic; $7 \mathrm{~mm}$ sodium phosphate, monobasic; $7 \mathrm{mM}$ sodium phosphate, tribasic), $1 \mathrm{mM}$ EDTA, and $2 \mathrm{mM}$ DTT. Upon activation, cathep$\sin$ B was incubated with Z-Arg-Arg-AMC substrate $(15 \mu \mathrm{M})$ and test compound in $10 \mu \mathrm{L}$ of assay buffer for $1 \mathrm{~h}$ at room temperature. Fluorescence of AMC released by enzyme-catalyzed hydrolysis of Z-Arg-Arg-AMC was read on a Perkin-Elmer Envision microplate reader (excitation $355 \mathrm{~nm}$, emission $460 \mathrm{~nm}$ ).

14. Characterization data for 1. $\mathrm{Mp}=167^{\circ} \mathrm{C}$; IR (thin film, $\left.\mathrm{CH}_{2} \mathrm{Cl}_{2}\right) 3479,3328,1733,1621,1189,610 \mathrm{~cm}^{-1} ;{ }^{1} \mathrm{H}$ NMR $\left(500 \mathrm{MHz}, \mathrm{DMSO}-d_{6}\right) \delta 8.11(\mathrm{~m}, 1 \mathrm{H}), 7.98(\mathrm{~m}, 1 \mathrm{H})$, $7.94(\mathrm{~m}, 2 \mathrm{H}), 7.79(\mathrm{~m}, 1 \mathrm{H}), 7.69(\mathrm{~m}, 2 \mathrm{H}), 7.29(\mathrm{~m}, 1 \mathrm{H})$, 6.57, (s, 3H), $5.36(\mathrm{~s}, 1 \mathrm{H}) ;{ }^{13} \mathrm{C}$ NMR $(125 \mathrm{MHz}, \mathrm{DMSO}-$ $\left.d_{6}\right) \delta 158.4,158.0,152.4,136.5,136.2,135.9,134.9,130.4$, 129.8, 128.9, 127.2, 80.5; high resolution mass spectrum (ES+) $m / z 350.0265\left[(\mathrm{M}+\mathrm{H})^{+}\right.$; calcd for $\mathrm{C}_{14} \mathrm{H}_{11} \mathrm{~N}_{3} \mathrm{O}_{4} \mathrm{~S}_{2} \mathrm{H}^{+}$: 350.0269].

15. A single crystal X-ray structure of pyrazole ester 2 was also obtained to verify its structure.

16. Elgemeie, G. H.; Metwally, N. H. J. Chem. Res. 1999, 6, 384.

17. Elgemeie, G. H.; Elghandour, A. H.; Elzanate, A. M.; Masoud, W. A. Phosphorus, Sulfur Silicon 2000, 163, 91.

18. For the cyclization of hydrazide-substituted ureas using this protocol, see: Drummond, J. T.; Johnson, G. J. Heterocycl. Chem. 1988, 25, 1123.

19. Vostrova, L. M.; Grenad'orova, M. V.; Klad'ko, L. G. Ukr. Khim. Zh. 2004, 9-10, 115.

20. PC Spartan is available from Wavefunction, Inc., 18401 Von Karman Avenue, Suite 370 Irvine, CA 92612.

21. Kim, M. J.; Yamamoto, D.; Matsumoto, K.; Inoue, M.; Ishida, T.; Mizuno, H.; Sumiya, S.; Kitamura, K. Bioche. J. 1992, 287, 797.

22. de Dios, A.; Prieto, L.; Martín, J. A.; Rubio, A.; Ezquerra, J.; Tebbe, M.; de Uralde, B. L.; Martín, J.; Sánchez, A.; LeTourneau, D. L.; McGee, J. E.; Boylan, C.; Parr, T. R.; Smith, M. C. J. Med. Chem. 2002, 45, 4559 . 
23. Segel, I. H. Enzyme Kinetics: Behavior and Analysis of Rapid Equilibrium and Steady-State Enzyme Systems; Wiley Classics Library, Wiley: New York, 1975, pp 100-112.

24. Reversibility of inhibition was demonstrated by incubating 1 at a concentration $10 \times \mathrm{IC}_{50}$ with enzyme at 100 -fold greater than the usual assay concentration for 15-min. Following the $15 \mathrm{~min}$ incubation the mixture was diluted 100 -fold into assay buffer containing substrate, and the enzyme was assayed. This dilution gave the usual assay concentration of enzyme, and 1 at $0.1 \times \mathrm{IC}_{50}$, a concentration at which most of the enzymatic activity should be regained if the compound is rapidly reversible.

25. Pyrazolones 12, 14, and $\mathbf{1 5}$ were found to be inactive in the cathepsin B assay.

26. Li, S.; Whorton, R. A. Anal. Biochem. 2002, 303, 217.

27. Wang, Q.; Dubé, D.; Friesen, R. W.; LeRiche, T. G.; Bateman, K. P.; Trimble, L.; Sanghara, J.; Pollex, R.; Ramachandran, C.; Gresser, M. J.; Huang, Z. Biochemistry 2004, 43, 4294.

28. Cline, D. J.; Redding, S. E.; Brohawan, S. G.; Psathas, J. N.; Schneider, J. P.; Thorpe, C. Biochemistry 2004, 43, 15195.
29. Denu, J. M.; Tanner, K. G. Biochemistry 1998, 37, 5633.

30. Tyulkova, N. A.; Krasnova, O. I. Formation of $\mathrm{H}_{2} \mathrm{O}_{2}$ in Bacterial Bioluminescence Reaction with Flavinmononucleotide Activated with $N$-methylimidazole on the Phosphate Group without Addition of the Exogenous Aldehyde. In Bioluminescence \& Chemiluminescence: Progress and Perspectives, Proceedings of the International Symposium on Bioluminescence \& Chemiluminescence, Yokohama, Japan, Aug 2-6, 2004; Tsuji, A., Ed.; World Scientific Publishing Co. Pte. Ltd: Singapore, 2005; CAN 144:65940, 91.

31. For the $\mathrm{p} K_{\mathrm{a}}$ of pyridine in water (5.2), see: Bordwell, F. G. Acc. Chem. Res. 1988, 21, 456.

32. For an insightful review of cysteine mechanism studies, see: Polgár, L.; Halász, P. Biochem. J. 1982, 207, 1.

33. Keillor, J. W.; Brown, R. S. J. Am. Chem. Soc. 1992, 114, 7983.

34. For an example of an ester substrate ( $N$-benzyloxycarbonyl-L-lysine $p$-nitrophenyl ester) of cathepsin B, see: Bajkowski, A. S.; Frankfater, A. J. Biol. Chem. 1983, 258, 1645. 